\title{
Biochemical Mediators and Mechanisms Involved in Chromatin Conformational Remodeling through the Cell Cycle
}

\author{
Ravi Maddaly, ${ }^{*}$ Kauser S. Begum, Aswathy S. Lal, \& Sraddha S. Bharadwaj \\ Department of Human Genetics, Faculty of Biomedical Sciences, Technology and Research, Sri Ramachandra \\ Medical College and Research Institute, Porur, Chennai, India \\ *Address all correspondence to: Dr. Ravi Maddaly, Professor, Department of Human Genetics, Faculty of Biomedical Sciences, Technology and \\ Research, Sri Ramachandra Medical College and Research Institute, Porur, Chennai-600116, India; Tel.: +91 44 24768027; Fax: +91 44 24767008, \\ E-mail: mravi@sriramachandra.edu.in
}

\begin{abstract}
Chromatin undergoes structural remodeling through the cell-cycle stages. Remodeling of the chromatin structure is extremely important for events occurring during these stages. The five major levels of structural organization, from the double-strand structure to the metaphase chromosomes are possible due to specific factors and mechanisms that function in synchrony. The mitotic promoting factors, the "structural maintenance of chromosomes" proteins, and proteins associated with cytoskeletal and nucleoskeletal elements have specific roles in structural modeling and functioning of DNA. It is of interest that the DNA decondensation cycle opposes the DNA condensation cycle. However, it is not clear if the factors and mechanisms involved in the DNA decondensation cycle are exactly opposite to the DNA condensation cycle. Also interesting is that chromosome-specific chromatin is positioned in the interphase nucleus in specific "territories" or "niches," a phenomenon similar to the exactly positioned genes at specific locations on a fully condensed chromosome. We review the factors and mechanisms in remodeling chromatin, maintaining structural integrity at each organizational level, and impact of this structural remodeling on functions of the genetic material.
\end{abstract}

KEY WORDS: chromatin remodeling, MPFs, SMCs, LINC complex, microskeletal network

\section{INTRODUCTION}

The cell cycle is a complex and dynamic physiological process that involves the orchestrated functioning of several cellular components. The mechanisms involve specific gene expressions, transcription of cell-stage-specific factors, and collaborations to induce dynamic changes in the chromatin structure and finally cell division. The stage-specific checkpoints, DNA repair mechanisms, and assembly of chromosomes at the mitotic plane followed by their segregation to the two poles of the dividing cell are of unrivaled complexity and perfect synchrony.

The cell-cycle stages are accompanied by the DNA condensation and decondensation cycles where chromatin undergoes a series of complex structural remodeling processes. Thus, the DNA double helix is remodeled into nucleosomes, chromatin fibers, and looped domains, finally attaining maximum compaction as metaphase chromosomes. The reverse structural conformation occurs as the metaphase-stage cell completes division and enters the $\mathrm{G}_{0}$ or $\mathrm{G}_{1}$ stage of the interphase, a series of steps comprising the DNA decondensation cycle.

Conformational remodeling of chromatin through the various stages of the cell cycle is dynamic and complex, requiring interactions of several proteins. Also, the type of association and the manner in which such associations remodel chromatin morphology are specific to the various levels of chromatin structural organization. Helicases, single-strand proteins, topoisomerases, and telomerases are the proteins associated with the fundamental morphological unit of DNA, the doublestrand structure. Helicases unwind the twisted DNA structure while single-strand proteins keep the template strands apart and prevent them from forming double strands. The topoisomerases reduce structural strain caused by helicases and telomerases to maintain structural integrity of the chromosome ends (telomeres). The histone proteins are important for the next level of morphological entities, 
the nucleosomes and chromatin fibers. Topoisomerases appear as the predominant proteins associated with the looped-domain structures, and several protein factors are involved in the initial organization of chromosome structures apart from their maintenance. ${ }^{1}$

The significance of the factors involved in chromatin morphological modeling lies with their precision. It is intriguing that the arrangement of chromosome-specific chromatin in the interphase nucleus is always location-specific. Hence, a specific designated site or niche within the interphase nucleus is well-determined for the chromatin belonging to a specific chromosome. ${ }^{2,3}$ The influence of the nuclear membrane, nuclear lamina, and microskeletal network of the nuclear membrane and the nucleoplasm on the orientation of chromatin in the interphase and during cell division is an area of recent interest. The binding of telomeric regions to specific components of the nuclear membrane during meiosis is now understood to influence the segregation of chromosomes to the two poles of a dividing cell. ${ }^{4}$

Chromatin remodeling comprises chromatin structural changes that are controlled by several factors. It occurs in collaboration with other events such as transcription or as an independent process. Certain remodeling stages require ATP, and some events involve covalent histone modifications. ${ }^{5,6,7}$ Disruption of these factors by any genetic or environmental factors can lead to cancer, genetic disorders, autism, and the like. Apart from helicases, topoisomerases, and telomerases, enzymes such as DNA translocases use ATP to move the histone octamer to different DNA sites to aid remodeling. Also, these different enzymes have unique positioning activities. The exact position depends mainly on the ATPase motor protein and the multiprotein complex where the enzymes are integrated. ${ }^{8}$ Thus, specific factors and mechanisms influence chromatin conformational remodeling throughout the cell cycle. It is still unclear if chromatin decondensation is an exact reverse of condensation, which occurs from interphase to metaphase, or if different factors and mechanisms are involved in decondensation. We present here the various factors in chromatin remodeling along with their mechanisms.

\section{STRUCTURAL ORGANIZATION OF CHROMATIN THROUGHOUT THE CELL CYCLE}

The structural organization of chromatin follows a specific sequence. Double-strand DNA of 2-nm diameter coils around an octamer of packaging proteins, histones. This produces the "string-of-beads" structures called nucleosomes. They represent the first level of packing, after which the DNA helix is condensed by winding around the histones. The nucleosome units join together to form a chromatin fiber of 11-nm diameter. The chromatin fibers further form a chromatin loop of 30-nm diameter, creating a much thicker structure, the solenoid. This, along with help from $\mathrm{H} 1$ proteins creates the second level of packing, making the DNA more compact, and is a characteristic of uncoiled chromatin fiber in the interphase stage of the cell cycle. The $30-\mathrm{nm}$ chromatin fiber undergoes further compaction to form coiled chromatin fibers of 300-nm diameter, which are compacted into the chromosomal arms of a chromatid, a subunit of metaphase chromosomes. ${ }^{9}$

\section{A. Protein and Nonprotein Factors}

The genome is condensed at various levels to arrive at the highly compact, coiled chromosome unit. These levels (as discussed earlier) are signified based on the proteins they are compiled with and the diameter of the structure. The four structural forms are the primary structure of nucleotides forming a single strand, the secondary structure of interaction between bases, the tertiary structure of the DNA double helix, and the quaternary structure of wound histone proteins and complex condensation resulting in specific chromosomal entities. Protein factors coming into play during the quaternary condensation stage serve two purposes. First, they stabilize the negatively charged DNA strand; second, they act as a spool around which the linear strand is wound in a circular fashion. This circular winding necessitates a certain amount of binding energy that needs to be stabilized in order to maintain the compactness of the structure. It has been established that the DNA double helix touches the histone octamer only in minor grooves of double-strand DNA which 
involves 14 patches of specific base pairs. Overall, 147 specific base pairs have been identified as possessing the ability to wrap around the octamer. ${ }^{10}$ These base pairs are sequences that can position the nucleosome; however, there are no base-specific interactions between the nucleosomes and the DNA. Nucleosomes have been observed to be specific to high-affinity sequences that have been proposed to signify a genomic code for nucleosomic positioning. These sequences are determined by AA, TT, and TA dinucleotides at binding sites (minor grooves facing inward toward the octamer) and increased occurrence of GC dinucleotides at nonbinding sites (minor grooves facing outward). This indicates that nucleosomes prefer to bind to high GC content and avoid transcriptionally active motifs. ${ }^{10,11,12}$ To bring about this sequence-specific remodeling, there are chromatin remodelers, which are variants of kinetic proofreading proteins for mRNA translations.

Liu et al. elucidated the mechanism of action for the ATPase unit of protein Snf2 using cryo-EM. ${ }^{13}$ The DNA strand winds around the histone octamer in 1.65 turns. The first round of winding has an open cleft at lobe 1 of the ATP-binding site at superhelical location 2. This site is also in contact with the second winding of the DNA helix 90 base pairs away. This second contact is through an acidic base with a closed cleft at lobe 2 of the ATP-binding site. Upon ATP binding due to ATPase, the first cleft closes and pushes the DNA strand 1 base pair up at the second cleft toward the nucleosome dyad across the histone octamer in the 90th base pair position. Once hydrolyzed, lobe 2 rests without sliding the DNA back with it. Thus, ATPase remains attached to lobe 1 at superhelical location 2 but lobe 2 dynamically resets upon translocation. ${ }^{12,13}$

The winding of DNA around the nucleosome does not satisfy chromosomal packing; multiple nucleosomes are arranged close to each other in order to condense at a higher density. The spacing of nucleosomes is also not random. It is responsible for bringing about various changes in protein levels such as increased intragenic transcription and changes in gene expressions. Thus, internucleosome spacing is a highly important epigenetic factor controlled by ATP-dependent chromatin-remodeling enzymes that organize nucleosomes in genomes that are partially redundant. The enzymes Chd 1 and ISWI belong to the family of Snf2-related chromatin proteins that function to reconfigure DNA-protein interactions. These genes are positioned on the nucleosomes in such a way that they overlap at transcriptional start sites in an organization that differentiates euchromatin from heterochromatin. Chd1 and ISWI enzymes consist of a DNA-binding C-terminal domain, sensitive to the epitope of the histone $\mathrm{H} 4 \mathrm{~N}$-terminal tail, which adapts them for the purpose of maintaining nucleosome spacing. ${ }^{12,14}$

Once the double helix has been condensed to form nucleosomes, the nucleosomes undergo further condensation to form loops. These loops are then circularly wound to produce rosette structures that are stacked one upon the other, resulting in a chromatin arm. Two such arms attached at the centromere form a chromosome. Cohesin is a protein found in the centromere and the arms of chromosomes. It is required in the centromeres to resist the pulling force from spindle fibers during chromosomal segregation, facilitating stabilization of microtubule-kinetochore attachments and chromosome biorientation. These proteins are also present at thousands of loci on chromosome arms almost $90 \%$ of which are binding sites for CCCTC binding factors (CTCFs). CTCFs are zinc-finger proteins that are responsible for inhibiting gene promoters from distant enhancers by creating allele-specific chromatin loops. Thus, it is proposed that during loop extrusions, CTCF sites play the role of directional boundary elements; loop lengths are determined by WAPL, the unloading factor, and PDS5, WaPL's binding factor. ${ }^{15}$

Maturation- promoting factors (MPFs) are dispersed in the cytoplasmic matrix and the nuclear matrix of a mitotic cell. They were first identified in oocytes and observed to induce germinal vesicle breakdown (GVBD), which gives them the ability to cause nuclear membrane disintegration and expose chromosomes to various proteins in the cytoplasm in order to initiate chromosome condensation. MPFs are presumed to be crucial players in progression through the cell cycle. They are evolutionarily conserved and found to be similar between vertebrates and invertebrates. ${ }^{16}$ Experiments with MPFs have shown that they cause chromosomal condensation 
in $\mathrm{G}_{0}$ or interphase cells. No additional processing is required by the exposed cellular machinery because MPFs come with their own autocatalytic activity. The exposed cell is then able to continue through chromatin condensation and mimic the behavior of a metaphase cell. ${ }^{17}$ When cells are exposed to UV irradiation, chromosome decondensation is induced. This is due to inhibitors of mitotic factors (IMFs). IMFs induce decondensation after their presence in the telophase. They are antagonistic to mitotic factors and thus regulate chromosome decondensation. ${ }^{18}$ The protein factors involved in the various levels of DNA and chromatin structural organization along with their functions are presented in Table 1.

\section{B. Maintenance of Integrity}

The structural organization of chromatin at various levels largely influences genome stability. Endogenous DNA damages are rectified by transcription and replication of DNA at different cell-cycle stages. ${ }^{19}$ This is crucial for maintenance of genomic stability because such damages represent massive threats to cells. Studies have shown that error-prone repair mechanisms such as nonhomologous end joining (NHEJ) cause certain major genomic alterations - for example, translocations and complex chromosome rearrangements. ${ }^{20,21}$ One event that follows DNA damage is histone $\mathrm{H} 2 \mathrm{~A}$ phosphorylation, which leads to the union of chromatin-modifying

TABLE 1: Structural organization of double-strand DNA molecule

\begin{tabular}{|c|c|c|c|c|}
\hline $\begin{array}{c}\text { Level of } \\
\text { organization }\end{array}$ & $\begin{array}{c}\text { Structural } \\
\text { features }\end{array}$ & Biochemical factors & $\begin{array}{c}\text { Physical dynamics/ } \\
\text { forces/mechanics }\end{array}$ & Functional significance \\
\hline Double helix & $\begin{array}{l}\text { 2-nm-diameter } \\
\text { double helix }\end{array}$ & $\begin{array}{l}\text { Nitrogenous bases join } \\
\text { by base pairing to give } \\
\text { double-helix structure }\end{array}$ & $\begin{array}{l}\text { Held together by } \\
\text { hydrogen bonds } \\
\text { between bases and } \\
\text { Van der Waals base- } \\
\text { stacking interaction; } \\
\text { phosphodiester bonds } \\
\text { become backbone }\end{array}$ & $\begin{array}{l}\text { Contains genetic } \\
\text { information and } \\
\text { facilitates replication }\end{array}$ \\
\hline Nucleosome & $\begin{array}{l}10 \text {-nm fibers } \\
\text { ("beads-on-a- } \\
\text { string") }\end{array}$ & $\begin{array}{l}\text { Interaction of histones } \\
\text { and DNA forms } \\
\text { nucleosomes; Histone } \\
\text { proteins } \mathrm{H} 2 \mathrm{~A}, \mathrm{H} 2 \mathrm{~B}, \mathrm{H} 3 \text {, } \\
\text { and } \mathrm{H} 4 \text { aid chemical } \\
\text { association of histones } \\
\text { and DNA }\end{array}$ & $\begin{array}{l}\text { Histone tail interactions } \\
\text { stabilize the nucleosome }\end{array}$ & $\begin{array}{l}\text { Plays role in gene } \\
\text { expression regulation } \\
\text { and interacts with } \\
\text { transcription machinery; } \\
\text { represents first level of } \\
\text { DNA compaction }\end{array}$ \\
\hline $\begin{array}{l}\text { Chromatin } \\
\text { fiber }\end{array}$ & 30-nm fibers & $\begin{array}{l}\text { Certain histone proteins, } \\
\text { chromatin-interacting } \\
\text { proteins (e.g., } \\
\text { transcriptional factors) } \\
\text { involved }\end{array}$ & $\begin{array}{l}\text { Anchored to nuclear } \\
\text { matrix with help } \\
\text { of scaffold/matrix } \\
\text { attachment regions }\end{array}$ & $\begin{array}{l}\text { Packages DNA into } \\
\text { more compact, denser } \\
\text { shape to prevent DNA } \\
\text { damage and facilitate } \\
\text { mitosis/meiosis }\end{array}$ \\
\hline $\begin{array}{l}\text { Chromatin } \\
\text { loops }\end{array}$ & $\begin{array}{l}\text { 300-nm domains } \\
\text { with looped } \\
\text { structures }\end{array}$ & $\begin{array}{l}\text { Chromatin remodeling } \\
\text { factors, histone- } \\
\text { modifying enzymes } \\
\text { involved }\end{array}$ & $\begin{array}{l}\text { Intermonomer attraction } \\
\text { and cohesins involved in } \\
\text { loop formation }\end{array}$ & $\begin{array}{l}\text { Transcriptional } \\
\text { regulation, maintenance } \\
\text { of higher-order } \\
\text { chromatin folding }\end{array}$ \\
\hline Chromosomes & $\begin{array}{l}\text { Chromatid of } \\
700 \text {-nm width; } \\
\text { complete } \\
\text { chromosome } \\
\text { 400-nm wide }\end{array}$ & $\begin{array}{l}\text { Loops tethered by } \\
\text { cohesins/scaffold } \\
\text { proteins form } \\
\text { chromosomes }\end{array}$ & $\begin{array}{l}\text { Condensation facilitates } \\
\text { sister chromatid linking } \\
\text { by centromere formation } \\
\text { to form chromosomes }\end{array}$ & $\begin{array}{l}\text { Final structure of DNA } \\
\text { folding as required } \\
\text { for chromosome } \\
\text { segregation during cell } \\
\text { division }\end{array}$ \\
\hline
\end{tabular}


factors near the damage site. These factors are capable of changing the structure of nucleosomal DNA, thereby allowing the repair mechanisms to fix the damages and maintain integrity. Members of the chromatin-modifying family include ATPdependent Rad54 and SWI/SNF as well as histone acetyl transferases such as p300/CBP and SAGA/ $\mathrm{NuA} 4$ complex. They influence the accessibility of DNA and its repair, resulting in genomic integrity maintenance. ${ }^{22}$

Multiple factors - chromatin remodeling, histone modification, and proteins referred to structural maintenance of chromosomes (SMCs)-help in modulating chromatin structural dynamics. However, there is a strong connection between chromatin organization and cell-cycle phase. A major breakthrough in understanding chromatin condensation was the discovery of SMCs. The three major protein SMCs are condensin I, condensin II, and cohesins. Condensins influence the shaping of chromosomes during cell division. Condensin I and condensin II are the two major subgroups. The intricate balance between condensin I and II levels leads to condensation of chromatin and chromosome structure maintenance. The presence of condensins is specific to certain cell-cycle phases. ${ }^{23}$ Condensin I is shown to influence chromosomes after the early mitosis stages, when the disintegration of the nuclear envelope occurs. Condensin II influences chromosomes from the beginning of the cell cycle. Both subgroups are known to be present in all cell-cycle stages. ${ }^{24}$ Levels of cohesin, which aids sister chromatid joining, are also specific to cell-cycle phases. They are always associated with chromosomes but their level increases during the prophase of mitosis and decreases as cells enter the metaphase; it disappears completely by the anaphase. This process helps cohesins pull the sister chromatids apart at the centromeric site. ${ }^{23}$

Another group of proteins, called survivins, belong to the inhibitor of apoptosis (IAP) family. IAP levels are high in cancer cells but are absent in nonproliferating normal cells. Studies have reported survivins in the G2/M phase but none at all in the interphase. However, increased survivin levels at the mitotic stage in normal cells facilitate chromosomal structural integrity. ${ }^{25}$

\section{NUCLEAR PROTEINS ASSOCIATED WITH CHROMATIN REMODELING AND STRUCTURAL ORIENTATION}

\section{A. Nuclear Microskeletal Factors and Nuclear Membrane Proteins}

The cytoplasm consists of actin polymers, microtubules, and intermediate filaments that anchor cellular organelles and maintain cellular morphology with an intricate network. This cytoskeleton comprises the KASH, LINC, and the SUN proteins. The salient features of these proteins along with their functions for chromatin remodeling are presented in Table 2. The nucleoskeleton is attached to these SUN proteins, forming an intricate network within the nuclear matrix holding the chromosomal niches in place. ${ }^{26}$ Interactions among the various proteins associated with the cytoskeletal elements, the nuclear membrane, and the chromatin within the nucleus for the positional organization of interphase chromatin are illustrated in Fig. 1.

The nuclear envelope confines the chromosomal material to a specific sphere and protects it from enzymatic degradation. All genetic material, which is made up of 22 pairs of autosomes and 1 pair of allosomes, have specific chromosomal territories or

TABLE 2: KASH and SUN membrane proteins

\begin{tabular}{|c|c|}
\hline Member & Function \\
\hline \multicolumn{2}{|c|}{ KASH Proteins } \\
\hline $\begin{array}{l}\text { Syne-1 (nesperin-1) } \\
\text { Syne-1(nesperin-2) }\end{array}$ & $\begin{array}{l}\text { Attach nuclei to actin filaments, } \\
\text { nucleokinesis }\end{array}$ \\
\hline Nesperin-3 & $\begin{array}{l}\text { Connects nucleus to } \\
\text { cytoskeleton }\end{array}$ \\
\hline Nesperin-4 & $\begin{array}{l}\text { Binding kinesin; cell } \\
\text { polarization }\end{array}$ \\
\hline KASH 5 & $\begin{array}{l}\text { Dynein-driven telomere } \\
\text { dynamics in meiosis }\end{array}$ \\
\hline \multicolumn{2}{|r|}{ SUN Proteins } \\
\hline $\begin{array}{l}\text { SUN } 1 \\
\text { SUN } 2\end{array}$ & $\begin{array}{l}\text { Movement/attachment of } \\
\text { telomeres, nuclear anchorage/ } \\
\text { migration, integrity of nuclear } \\
\text { envelope }\end{array}$ \\
\hline SUN 3 & $\begin{array}{l}\text { Sperm formation-links nucleus } \\
\text { to head }\end{array}$ \\
\hline
\end{tabular}



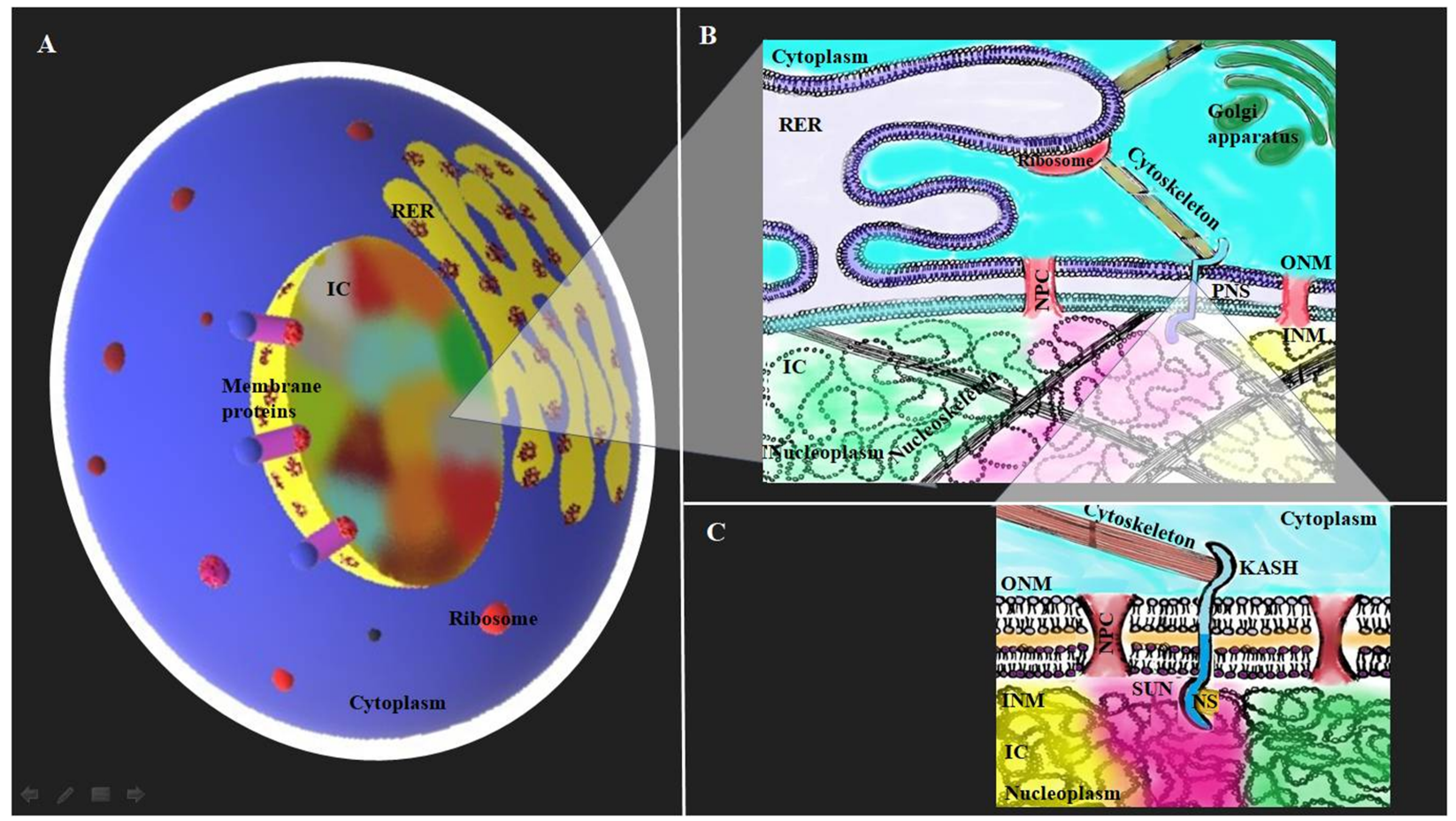

FIG. 1: (A) Cell in the interphase with a central prominent nucleus extending into the RER and chromosome-specific chromatin in specific territories, or niches. (B) Nuclear membrane and associated proteins important for chromatin or chromosome positioning. The ONM and INM are sites where membrane proteins link the cytoskeleton to the nucleoskeleton. (C) Protein complex comprising the KASH membrane proteins on the ONM and the SUN that span the INM. KASH proteins have an N-terminal domain attached to the cytoskeleton fibers; a hydrophobic transmembrane sequence extends into the PNS, ending with a C-terminal 4-amino acid moiety. The C-terminal moiety is in conjugation with the C-terminal amino acid of the SUN membrane protein in the PNS, and the N-terminal domain of the SUN proteins extend into the nucleoplasm and is in contact with the nucleoskeleton network. The KASH C-terminal domain and SUN C-terminal domain complex together comprise the LINC in the PNS that bridges the gap between the cytoskeleton and the nucleoskeleton. The nucleoskeleton fibers are attached to the chromatids to hold them in their niches in the nuclear sphere. The niches are specific to each chromosome and are disrupted only during cell division. During cell division, the nucleoskeleton attaches to the telomeres and centromeres for exact positioning and movement of chromosomes during cell division.

niches that are occupied by each of these 23 pairs. These designated areas are maintained by the nucleoskeleton and cytoskeleton filaments that hold each individual chromosome in place. It has been observed that the two homologous pairs of chromosomes are not located within a common periphery but rather at a distance. This overall arrangement has been deduced to endure transcription, where the euchromatin (transcriptionally active) is more exposed and easily accessible by the transcription factors and vice versa. As the cell cycle progresses, the chromosomal territories are disturbed to make way for duplication and segregation. Thus, the nuclear envelope and the nucleoskeleton disintegrate to make way for this profound pathway. ${ }^{27}$

The nuclear membrane is a bilipid layer 20$40 \mathrm{~nm}$ in length. The outer nuclear membrane (ONM) is a special continuation of the rough endoplasmic reticulum. It has attached ribosomes that serve as sites for protein synthesis. The inner nuclear membrane (INM) holds the nuclear matrix inside the nucleus. Between the outer and the inner membranes is the perinuclear space (PNS), which is devoid of matrix. Pores connecting the outer and 
inner membranes run through the PNS to facilitate the movement of proteins in and out of the nucleus. The pores are highly specific in function based on selective transport and size $(100 \mathrm{~nm}){ }^{4,26}$

In addition to pores, linkers (LINCs) between the nucleoskeleton the and cytoskeleton keep the nucleus in the correct position and configuration within the cellular matrix. LINCs are responsible for the stability of the nuclear structure and have various roles in cellular division, migration, and differentiation, to name a few. ${ }^{26,28}$ From a structural point of view, the ONM and the INM have different origins. The ONM is a continuation of the endoplasmic reticulum, which has ribosomes associated with KASH membrane proteins, whereas the INM is the lamina specific to the nucleus and is associated with SUN membrane proteins. The ONM binds cytoskeleton components to microtubules, which are extremely important during cell progression from the metaphase plate formation to the anaphase. ${ }^{4}$

The KASH membrane proteins have a structure of N-terminal domains connected to the cytoskeleton. A 6-30-amino acid hydrophobic transmembrane sequence in the perinuclear space and a C-terminal 4-amino acid motif domain connect to the SUN membrane proteins. The proteins in the KASH and SUN groups, which are present predominantly in mammals, are listed in Table 2. The SUN membrane proteins have a structure of $\mathrm{N}$-terminal domains with the lamina of the nucleoskeleton, and tethers chromosomes to the nuclear periphery and a C-terminal extending into the perinuclear space and connecting to the KASH proteins. Most proteins have a coiled domain at the $\mathrm{N}$-terminus to aid protein trimerization. Functions include nuclear positioning and linking the centrosome to the nucleus for the special distribution of ONMs and INMs and spindle architecture. During meiosis, SUN proteins are required for pairing centromeres to the nuclear envelope or for attaching telomeres to the nuclear envelope. ${ }^{4,26,28,29}$

\section{B. LINC Complexes (Linker of Nucleoskeleton and Cytoskeleton)}

As mentioned above, the cytoskeleton induces mobility through telomere-nuclear envelope attach- ments. Cytoskeletal forces are in turn transferred to the nucleoskeletal forces to influence and induce movement in the chromosomes. The molecular machinery connecting the cytoskeleton to the nucleoskeleton includes the tubules around the nucleus. These are situated in the cytoplasm and connect to the KASH proteins located on the ONM in conjugation with the SUN proteins located in the INM. The SUN proteins are connected to the nucleoskeleton spanning the entire nucleus. The LINC complexes span the perinuclear space between the ONM and the INM, bridging the gap between the KASH membrane proteins and the SUN membrane proteins. Through this complex network, chromosomes are adhered to their specific chromosomal niches or moved to facilitate their repair or segregation into the two progeny cells. ${ }^{4}$

\section{Association of the Nuclear Envelope and Telomeres during Meiosis}

Telomeres are repetitive sequences present on both ends of the $\mathrm{p}$ and $\mathrm{q}$ arms of chromosomes. They have a protective nature, functioning against nucleolytic degradation and fusion of two chromosomes. Recent studies have deduced that telomeres are physically attached to the nuclear envelope to govern the chromosomal movements during the cellular division cycle. ${ }^{30,31}$ During meiosis, in the meiotic interphase of prophase I, telomeres are attached to the nucleolus. As the cycle progresses, before the chromosomes pair up for crossover in the pachytene stage, telomeres attach to the nuclear envelope. Once attached, the telomeres move to a specific region, forming a "bouquet" with a unique arrangement. The clustering step occurring at the end of the leptotene stage persists in the zygotene and pachytene stages until chiasmata are formed and crossover takes place. Due to the accumulation of homologous chromosomes in a confined area, chromosome pairing and synapsis are facilitated to enable efficient crossover of genetic material and recombination of genes. After this stage, the telomeres are scattered again and evenly distributed across the nuclear envelope. Telomere-guided movement of chromosomes has been evolutionarily conserved and persists irrespective of the size of the organism's genome. . $^{32,33,4}$ 


\section{Association of Nuclear Membrane Disintegration and Chromosome Behavior during Karyokinesis}

A cell in the interphase stage maintains a functional nuclear envelope that serves as a barrier between the cytosol and the chromatin contents. When the cell is pushed into division, the membrane must break down in order to facilitate the distribution of chromosomes into two daughter cells. This process of nuclear dismantling is termed nuclear envelope breakdown (NEBD), and it involves the breakdown of the bilipid layer. The breakdown is initiated in a sequence of steps that occur within in a few minutes during the prophase of the cell cycle. It begins when nucleoproteins (nups) from the nuclear pore complexes (NPCs) undergo a selective loss led by Nup28 followed by a synchronous loss of the rest of the nups. It has been suggested that the nuclear envelope disintegrates into stable subcomplexes rather than individual polypeptides, which enhances its reforming at the end of karyokinesis. Degradation of NPCs is important for permeabilization and formation of spindle fibers. Linder et al. showed that degradation occurs when CDK1 and pololike kinase 1 (PLK1) are hyperphosphorylated and Nup98 (gatekeeper nucleoporin) and Nup53 disrupt the nucleoporin linking between the inner NPCs and the scaffold, causing disassembly of the entire unit. ${ }^{35}$ The ONM is closely associated with the rough endoplasmic reticulum (RER). Electron microscopy shows that, when nuclear degradation into subcomplexes occurs, the RER reabsorbs the degraded nuclear membrane units. Nups expelled into the cytosol move on to fulfil critical functions in mitosis. The multimeric Nup107-160 complex, which in the nucleoplasm brings about pore assembly and functioning, is associated with kinetochores, spindle pores, and proximal microtubules during mitosis. ${ }^{35}$

The nucleoskeleton also undergoes rearrangement during mitosis. In an interphase cell, the LINC complex connects the centromeres of chromosomes to the centrosomes present on the nuclear envelope. As the nuclear membrane disintegrates during progress through the cell-cycle stages, the connection evolves into attaching centrosomes to telomeres to facilitate chromosomal movements and segregation as explained above. Loss of telomere-LINC contacts disrupts meiotic spindle formation. ${ }^{36}$

\section{E. Nucleoplasm}

A typical nucleoplasm contains various nuclear bodies with different sizes and moieties. The nucleolus was the first subcellular compartment discovered having a size up to $8 \mu \mathrm{m}$ with a $25 \%$ nuclear volume. It is a site of ribosomal RNAs synthesis and ribosomal assembly. The nucleolus contains small round structures, Cajal bodies, with sizes ranging $0.1-3 \mu \mathrm{m}$. These have a characteristic protein called coilin which is responsible for assembly or modification of snRNPs. Gems bodies are found in close association with Cajal bodies. Normally known as its twin, Gems bodies are responsible for splicing and lack coilin proteins. Promyelocytic leukemia (PML) bodies are structures of $0.2-1 \mu \mathrm{m}$ in diameter found close to the INM that are responsible for chromatin structure modulation, chromatin contact generation, and gene expression. The number of such bodies in the nucleus varies from 5 to 10 depending on the cell-cycle stage. Speckles and Paraspeckles are proteins that are distributed throughout the nucleoplasm. Present in the interchromatin space, they function as a reservoir of splicing proteins, and are found at higher concentrations at sites of transcription activity. ${ }^{37}$

\section{FUNCTIONAL SIGNIFICANCE OF CHROMATIN MORPHOLOGY AND TRANSCRIPTION THROUGH THE CELL CYCLE}

Studies show that chromatin structure has notable effects on DNA metabolic processes such as recombination, repair, replication, and transcription. As a consequence of chromatin remodeling, the terminal parts of the DNA are unwrapped from the histone octamer forming a DNA loop; as a result, the nucleosomes are repositioned, further altering the accessibility of DNA to transcriptional factors. For this reason, two groups of chromatin-modifying enzymes act to increase DNA accessibility to the transcription machinery. When one group helps in influencing the action of DNA or histone interacting 
factors through modifications such as acetylation, ubiquitination, phosphorylation, and methylation, the other group breaks the histone-DNA links in the nucleosome via ATP hydrolysis. ${ }^{38}$ Many of these enzymes are part of the coregulator complex, which functions together with the transcription factors, to modulate gene expression. The heterogeneous composition of these complexes can affect the DNA functional specificity. ${ }^{39,40,41}$ The role of chromatin during transcription was first described in the early 2000s. In transcription, the promoters are bound to the activators to trigger a series of recruitment coactivator complexes. Coactivators such as histone-modifying enzymes, remodeling complexes, and mediators help in binding the DNA activators strongly to the DNA and make nucleosomal DNA more accessible to transcription factors. ${ }^{42}$

Chromatin is highly dynamic in actively cycling cells. During the S phase, new histones are added to the DNA, which calls for histone modifications. During mitosis, proper chromosome condensation and segregation occur when the chromatin modifiers are removed from the chromatin. Regulation of histone modifier activity can be dependent on the cell cycle. Cells undergo transition from rapidly proliferating to slow cycling, which ultimately may result in $\mathrm{G}_{0}$ entry and terminal differentiation. Hence, differentiation as well as cell-cycle dynamics can influence chromatin organization and modification. ${ }^{43}$

\section{PHYSICAL DYNAMICS/FORCES/ MECHANICS OF CHROMATIN REMODELING}

Many factors, such as transcription and other biological functions, come together to ease chromatin loop formation through some structural changes. These changes are facilitated by both proteins and physical effects such as macromolecular crowding and depletion attraction. Chromatin movement is modulated by a fragile balance of driving forces including viscoelastic resistance and molecular motors. Certain studies have shown that, when the nucleus distorts under high strain, the viscoelastic chromatin fiber acts as the dominant mechanical element. ${ }^{22,44}$

Macromolecular crowding plays a pivotal role in chromatin structure. Experiments have proved a clear connection between macromolecular crowding agents and chromatin compaction, with the two directly proportional to each other. As the concentration of these macromolecular agents increases, chromatin condensation also increases. It has also been proved that the ionic strength of the buffer used in in vitro experiments affects chromatin structure as well mainly because of the strong negative charge of chromatin. Macromolecular agents can thus reverse chromatin structure. This means that macromolecular crowding maintains chromatin integrity alone and in association with ionic conditions. ${ }^{45}$ In such crowded environments, depletion attraction occurs which is a kind of attractive force that assists in the assembly of cellular structures from the cytoskeleton to the chromatin loops. ${ }^{46}$

\section{COMPUTATIONAL MODELING TO UNDERSTAND CHROMATIN STRUCTURE}

The recent computational developments in facilitate isolation of a single chromatid, anchoring one end of the chromatin fiber and pulling the other end. This causes the nucleosomal bonds to break so that the force-length relationship can be assessed. Computational remodeling promotes better understanding of chromatin structural organization. Currently available mesoscale modeling programs have inbuilt information on the nucleosome, H1, and linker DNA along with their respective ionic environments, making it feasible to elucidate the structure of a sample chromatin. With each program run, different final structures can be obtained due to the stochastic nature of interactions. The final structures show the organization as fibers and not as clusters of nucleosomes. Modeling results are dependent on the accuracy of the input data, and certain limitations prevent the analysis of atomic-level structures. However, it is now possible to sample a wide range of conditions. Further advancements in computational modeling are likely to provide better insights regarding chromatin structure..$^{47,48}$

\section{CONCLUSION}

Genetic material goes through various stages of condensation and related remodeling as it passes 
through the cell-cycle stages. This leads not only to increased functioning but also maintenance of species-specific genomic distribution during cell division. The machinery involved in this process is highly specific and tailor-made to suit the requirements of each stage.

The factors involved in chromatin remodeling include both biochemical components and physical entities such as the microskeletal networks of the cytoplasm, the nucleus, and the nuclear membrane. There exists a complex network between the cytoskeletal fibers, the nuclear membrane proteins, and the nucleoskeletal fibers which enables communication between the cellular matrix and the chromatids in the nucleus. Also, chromatin condensation and decondensation are well regulated and well orchestrated events.

Understanding chromatin remodeling is important to arrive at a "structure-function" relationship of genetic material, which can be better elucidated because of advancements in OMICS technologies and computational tools. Apart from explanations of the biochemical mechanisms of DNA's morphological behavior through the cell cycle, research on chromatin remodeling provides practical applications such as prophasing interphase chromatin for use in genotoxicity studies.

\section{REFERENCES}

1. Lodish H, Berk A, Zipursky SL, Matsudaira P, Baltimore D, Darnell J. Molecular biology of the cell. 4th ed. New York: W. H. Freeman; 2000.

2. Lichter P, Cremer T, Borden J, Manuelidis L, Ward DC. Delineation of individual human chromosomes in metaphase and interphase cells by in situ suppression hybridization using recombinant DNA libraries. Hum Genet. 1988 Nov 1;80(3):224-34.

3. Manuelidis L. Individual interphase chromosome domains revealed by in situ hybridization. Hum Genet. 1985 Dec 1;71(4):288-93.

4. Zeng X, Li K, Yuan R, Gao H, Luo J, Liu F, Wu Y, Wu G, Yan X. Nuclear envelope-associated chromosome dynamics during meiotic prophase I. Front Cell Dev Biol. 2018 Jan 9;5:121.

5. Cairns BR, Lorch Y, Li Y, Zhang M, Lacomis L, Erdjument-Bromage H, Tempst P, Du J, Laurent B, Kornberg RD. RSC, an essential, abundant chromatin-remodeling complex. Cell. 1996 Dec 27;87(7):1249-60.

6. Varga-Weisz PD, Wilm M, Bonte E, Dumas K, Mann M,
Becker PB. Chromatin-remodelling factor CHRAC contains the ATPases ISWI and topoisomerase II. Nature. 1997 Aug;388(6642):598-602.

7. Ito $\mathrm{T}$, Bulger M, Pazin MJ, Kobayashi R, Kadonaga JT. ACF, an ISWI-containing and ATP-utilizing chromatin assembly and remodeling factor. Cell. $1997 \mathrm{Jul}$ 11;90(1):145-55.

8. Clapier CR, Iwasa J, Cairns BR, Peterson CL. Mechanisms of action and regulation of ATP-dependent chromatin-remodelling complexes. Nat Rev Mol Cell Biol. 2017 Jul;18(7):407.

9. Klug W, Cummings M, Spencer C, Palladino M. Concepts of genetics. Upper Saddle River, NJ: Pearson; 2019. p. 356-71.

10. Segal E, Fondufe-Mittendorf Y, Chen L, Thåström A, Field Y, Moore IK, Wang JP, Widom J. A genomic code for nucleosome positioning. Nature. 2006 Aug;442(7104):772-78.

11. Satchwell SC, Drew HR, Travers AA. Sequence periodicities in chicken nucleosome core DNA. J Mol Biol. 1986 Oct 20;191(4):659-75.

12. Blossey R, Schiessel H. The latest twists in chromatin remodeling. Biophys J. 2018 Jan 6:12.0018.

13. Liu X, Li M, Xia X, Li X, Chen Z. Mechanism of chromatin remodelling revealed by the Snf2-nucleosome structure. Nature. 2017 Apr;544(7651):440.

14. Sundaramoorthy R, Hughes AL, Singh V, Wiechens N, Ryan DP, El-Mkami H, Petoukhov M, Svergun DI, Treutlein B, Quack S, Fischer M. Structural reorganization of the chromatin remodeling enzyme Chd1 upon engagement with nucleosomes. Elife. 2017 Mar 23;6: e22510.

15. Wutz G, Várnai C, Nagasaka K, Cisneros DA, Stocsits RR, Tang W, Schoenfelder S, Jessberger G, Muhar M, Hossain MJ, Walther N. Topologically associating domains and chromatin loops depend on cohesin and are regulated by CTCF, WAPL, and PDS5 proteins. EMBO J. 2017 Dec 15;36(24):3573-99.

16. Kishimoto T, Kuriyama R, Kondo H, Kanatani H. Generality of the action of various maturation-promoting factors. Exp Cell Res. 1982 Jan 1;137(1):121-6.

17. Drury KC, Schorderet-Slatkine S. Effects of cycloheximide on the "autocatalytic" nature of the maturation promoting factor (MPF) in oocytes of Xenopus laevis. Cell. 1975 Mar 1;4(3):269-74.

18. Adlakha RC, Sahasrabuddhe CG, Wright DA, Rao PN. Evidence for the presence of inhibitors of mitotic factors during G1 period in mammalian cells. J Cell Biol. 1983 Dec 1;97(6):1707-13.

19. Nair N, Shoaib M, Sørensen CS. Chromatin dynamics in genome stability: roles in suppressing endogenous DNA damage and facilitating DNA repair. Int J Mol Sci. 2017 Jul 10;18(7):1486.

20. Simsek D, Brunet E, Wong SY, Katyal S, Gao Y, McKinnon PJ, Lou J, Zhang L, Li J, Rebar EJ, Gregory PD. DNA ligase III promotes alternative nonhomologous 
end-joining during chromosomal translocation formation. PLoS Genet. 2011 Jun 2;7(6):e1002080.

21. Zhang Y, Jasin M. An essential role for CtIP in chromosomal translocation formation through an alternative end-joining pathway. Nat Struct Mol Biol. 2011 Jan;18(1):80-4.

22. Spagnol ST, Armiger TJ, Dahl KN. Mechanobiology of chromatin and the nuclear interior. Cell Mol Bioeng. 2016 Jun 1;9(2):268-76.

23. Ravi M, Nivedita K, Pai GM. Chromatin condensation dynamics and implications of induced premature chromosome condensation. Biochimie. 2013 Feb 1;95(2):124-33.

24. Shintomi K, Hirano T. The relative ratio of condensin I to II determines chromosome shapes. Genes Dev. 2011 Jun 29;15:e1464-1469.

25. Jacob NK, Cooley JV, Shirai K, Chakravarti A. Survivin splice variants are not essential for mitotic progression or inhibition of apoptosis induced by doxorubicin and radiation. OncoTargets Ther. 2012;5:7e20.

26. Crisp M, Liu Q, Roux K, Rattner JB, Shanahan C, Burke B, Stahl PD, Hodzic D. Coupling of the nucleus and cytoplasm: role of the LINC complex. J Cell Biol. 2006 Jan 2;172(1):41-53.

27. Andrés V, González JM. Role of A-type lamins in signaling, transcription, and chromatin organization. J Cell Biol. 2009 Dec 28;187(7):945-57.

28. Sosa BA, Rothballer A, Kutay U, Schwartz TU. LINC complexes form by binding of three KASH peptides to domain interfaces of trimeric SUN proteins. Cell. 2012 May 25;149(5):1035-47.

29. Lee KK, Starr D, Cohen M, Liu J, Han M, Wilson KL, Gruenbaum Y. Lamin-dependent localization of UNC-84, a protein required for nuclear migration in Caenorhabditis elegans. Mol Biol Cell. 2002 Mar 1;13(3):892-901.

30. Koszul R, Kleckner N. Dynamic chromosome movements during meiosis: a way to eliminate unwanted connections? Trends Cell Biol. 2009 Dec 31;19(12):716-24.

31. Sheehan MJ, Pawlowski WP. Live imaging of rapid chromosome movements in meiotic prophase I in maize. Proc Natl Acad Sci USA. 2009 Nov 18;106:20989-94.

32. Bass HW. Telomere dynamics unique to meiotic prophase: formation and significance of the bouquet. Cell Mol Life Sci. 2003 Nov 1;60(11):2319-24.

33. Scherthan H. A bouquet makes ends meet. Nat Rev MolCell Biol. 2001;2:621-7.

34. Linder MI, Köhler M, Boersema P, Weberruss M, Wandke C, Marino J, Ashiono C, Picotti P, Antonin W, Kutay U. Mitotic disassembly of nuclear pore complexes involves CDK1-and PLK1-mediated phosphorylation of key interconnecting nucleoporins. Dev Cell. 2017 Oct 23;43(2):141-56.

35. D'angelo MA, Anderson DJ, Richard E, Hetzer MW. Nuclear pores form de novo from both sides of the nuclear envelope. Science. 2006 Apr 21;312(5772):440-3.

36. Fernández-Álvarez A, Bez C, O’Toole ET, Morphew M, Cooper JP. Mitotic nuclear envelope breakdown and spindle nucleation are controlled by interphase contacts between centromeres and the nuclear envelope. Dev Cell. 2016 Dec 5;39(5):544-59.

37. Nunes VS, Moretti NS. Nuclear subcompartments: an overview. Cell Biol Int. 2017 Jan;41(1):2-7.

38. Allard S, Masson JY, Côté J. Chromatin remodeling and the maintenance of genome integrity. Biochim Biophys Acta (BBA)-Gene Struct Expres. 2004 Mar 15;1677(1-3):158-64.

39. Tavares L, Dimitrova E, Oxley D, Webster J, Poot R, Demmers J, Bezstarosti K, Taylor S, Ura H, Koide H, Wutz A. RYBP-PRC1 complexes mediate H2A ubiquitylation at polycomb target sites independently of PRC2 and H3K27me3. Cell. 2012 Feb 17;148(4):664-78.

40. Gao Z, Zhang J, Bonasio R, Strino F, Sawai A, Parisi F, Kluger Y, Reinberg D. PCGF homologs, CBX proteins, and RYBP define functionally distinct PRC1 family complexes. Mol Cell. 2012 Feb 10;45(3):344-56.

41. Chen T, Dent SY. Chromatin modifiers and remodellers: regulators of cellular differentiation. Nat Rev Genet. 2014 Feb;15(2):93.

42. Li B, Carey M, Workman JL. The role of chromatin during transcription. Cell. 2007 Feb 23;128(4):707-19.

43. Ma Y, Buttitta L. Chromatin organization changes during the establishment and maintenance of the postmitotic state. Epigen Chromatin. 2017 Dec;10(1):53.

44. Pajerowski JD, Dahl KN, Zhong FL, Sammak PJ, Discher DE. Physical plasticity of the nucleus in stem cell differentiation. Proc Natl Acad Sci USA. 2007 Oct 2;104(40):15619-24.

45. Iborra FJ. Can visco-elastic phase separation, macromolecular crowding and colloidal physics explain nuclear organisation? Theor Biol Med Model. 2007 Dec;4(1):15.

46. Marenduzzo D, Finan K, Cook PR. The depletion attraction: an underappreciated force driving cellular organization. J Cell Biol. 2006 Dec 4;175(5):681-6.

47. Arya G, Schlick T. Role of histone tails in chromatin folding revealed by a mesoscopic oligonucleosome model. Proc Natl Acad Sci USA. 2006 Oct 31;103(44):16236-41.

48. Woodcock CL, Ghosh RP. Chromatin higher-order structure and dynamics. Cold Spring Harb Perspect Biol. 2010 Apr 7:a000596. 
